\title{
Composition of lower urinary tract stones in canines in Mexico City
}

\author{
Javier Del Angel-Caraza • Inmaculada Diez-Prieto • \\ Carlos César Pérez-García . \\ Ma Belén García-Rodríguez
}

Received: 25 August 2009/Accepted: 27 November 2009/Published online: 15 January 2010 (C) Springer-Verlag 2009

\begin{abstract}
Effective long-term management of urolithiasis depends on identification and manipulation of factors contributing to initial stone formation; identification of these factors depends on accurate identification of the mineral composition of the urolith involved. The purpose of this study was to determine the chemical composition of uroliths obtained from the low urinary tract of dogs in Mexico City. One hundred and five cases of urolithiasis were studied in which stones were surgically obtained from the low urinary tracts of dogs treated in different hospitals. The chemical composition of the uroliths was quantitatively and qualitatively determined by stereoscopic microscopy, IR-spectroscopy, scanning electron microscopy and X-ray microanalysis. Age of animals ranged from 4 months to 14 years, with a median of 5 years. Composition and distribution of the uroliths were struvite $38.1 \%$,
\end{abstract}

11th International symposium on urolithiasis, Nice, France, 2-5 September 2008 Urological Research (2008) 36:157-232. doi:10.1007/s00240-008-0145-5. http://www.springerlink.com/ content/x263655772684210/fulltext.pdf.

J. Del Angel-Caraza ( $\square)$

Hospital Veterinario para Pequeñas Especies,

Facultad de Medicina Veterinaria y Zootecnia,

Universidad Autónoma del Estado de México (UAEMéx),

Jesús Carranza \# 203, Col. Universidad, CP 50130 Toluca,

Estado de México, Mexico

e-mail: dlangel@uaemex.mx

J. Del Angel-Caraza · I. Diez-Prieto · C. C. Pérez-García ·

M. B. García-Rodríguez

Laboratorio de Investigación en Urolitiasis,

Depto. Medicina, Cirugía y Anatomía Veterinaria,

Universidad de León, León, Spain calcium oxalate $26.7 \%$, silica $13.3 \%$, urate $7.6 \%$, mixed $11.4 \%$, compounds $1.9 \%$, and cystine $1 \%$. Most uroliths were found in pure breed dogs $(75.2 \%) ; 23$ different breeds were identified, and more than half of the submissions were from breeds of small size. In our study, the frequency of struvite, calcium oxalate, cystine, urates, mixed and compounds stones are in agreement with papers that report on dog populations in America and Europe, but a higher frequency of silica uroliths was observed in Mexico City dogs.

Keywords Urinary stone - Mineral composition . Lower urinary tract $\cdot$ Dog

\section{Introduction}

Urolithiasis is a common disorder in dogs in all geographical areas, with diagnoses reaching $18 \%$ of dogs presenting with lower urinary tract disease [1]. The proportion of dogs with urolithiasis out of all dogs admitted to veterinary hospitals varies between 0.5 and $3 \%$ [1-3].

To achieve adequate control and long-term clinical management of this disease, it is necessary to identify the pathophysiological mechanisms involved, which requires knowing the mineral composition of the uroliths themselves. To determine such composition, it is necessary to perform a quantitative analysis, often combining more than one analytic method, such as stereoscopic microscopy, X-ray diffraction and/or infrared spectroscopy.

The purpose of this study was to determine the chemical composition of uroliths surgically obtained in dogs from Mexico City and to compare results with findings from studies in other geographical areas. 


\section{Materials and methods}

One hundred and five uroliths surgically removed from the low urinary tracts of dogs in Mexico City were analyzed with stereoscopic microscopy (zoom Stereomicroscope SWZ1500, Nikon Instruments, Japan), IR-spectroscopy (FT-IR 2000, Perkin Elmer, UK) with an infrared spectra library (IR Kidney Stones Spectra, Nikodom. Czech Republic) and, in some cases, with scanning electron microscopy (Jeol JSM-6480LV, Jeol, Japan) and X-ray microanalysis (INCA, Oxford Instruments, UK).

Uroliths were classified as simple or pure (one layer containing $\geq 70 \%$ of a given mineral), mixed (one layer with less than $70 \%$ of a single mineral) and compound (uroliths with nidus and other layers of varying predominant mineral composition), according to the usual veterinary classification [4].

We identified uroliths from a total of 23 different breeds (plus a group of mixed breed dogs), ranging in age from 4 months to 14 years, with a median age of 5 years.

\section{Results}

The distribution and composition of uroliths according to sex and age of the animals are presented in Table 1.

Overall, nearly two of every three uroliths $(63.8 \%)$ were from males, while slightly over one-third (36.2\%) occurred in females: a ratio of 1.76:1. Struvite uroliths were slightly more common in females (1:1.5), whereas in males, oxalate (3.65:1) and urate (1.6:1) uroliths were more frequently found. Silica uroliths and cystine uroliths were found exclusively in males.

Most samples $(75.2 \%, n=79)$ were from pure breed dogs. When considering the size of the animals, it was found that the samples obtained from small pure breed animals (less than $50 \mathrm{~cm}$ in height at adulthood) accounted for $72.2 \%(n=57)$. The breeds most commonly affected among small breeds were the miniature Schnauzer $(n=23)$, Poodle $(n=15)$, Yorkshire terrier $(n=6)$ and Cocker spaniel $(n=4)$; whereas among large breeds, Labrador retrievers $(n=7)$ and Dalmatians $(n=5)$ constituted the largest number of cases.

The composition of uroliths according to the size of the affected animals is presented in Table 2. It is noted that small breeds are mainly affected by struvite and calcium oxalate uroliths, while large breeds are predominantly affected by silica uroliths.

Overall, struvite uroliths accounted for nearly $40 \%$ of the total, followed by calcium oxalate (about $28 \%$ ), silicate (nearly 14\%) and mixed, which accounted for $11.4 \%$ of all cases. Mixed uroliths were found to be formed by combinations of ammonium urate and calcium oxalate $(n=7)$ or struvite with either calcium oxalate $(n=3)$ or calcium phosphate $(n=2)$. The two-compound uroliths each had a silica nidus with the other layer made of calcium oxalate.

Struvite was the only mineral present in uroliths of animals less than 1 year old. The age group most affected, regardless of the composition of the urolith, was 4-6 years.

\section{Discussion}

Over the past 30 years local, national and international epidemiological studies have published data on populations of dogs in different geographical areas; comparison of our results of these studies can be found in Table 3. Besides the geographical area involved, these studies also differ in the number of samples tested and the study periods. Despite these differences, all the studies analyzed the uroliths by physical techniques of quantitative analysis.

In our study, as in most reports found in the literature [4-8, 10], struvite uroliths were the most frequently encountered. These uroliths are frequently present in alkaline urine oversaturated with phosphate, ammonium and magnesium. This condition is usually associated with urinary tract infection by urease positive bacteria (Staphylococcus spp., Streptococcus spp. or Proteus spp.) [11].

Table 1 Composition and distribution of uroliths by sex and age $(n=105)$

\begin{tabular}{|c|c|c|c|c|c|c|c|c|}
\hline \multirow[t]{2}{*}{ Mineral } & \multirow{2}{*}{$\begin{array}{l}\text { Percentage }(n) \text { of } \\
\text { total analyzed }\end{array}$} & \multicolumn{2}{|l|}{ Sex } & \multicolumn{5}{|c|}{ Percentage by age range (years) } \\
\hline & & Female (\%) & Male (\%) & $<1.0$ & $1-3$ & $4-6$ & $7-9$ & $>10$ \\
\hline Struvite & $38.1(40)$ & 60 & 40 & 15 & 27.5 & 30 & 7.5 & 20 \\
\hline $\mathrm{CaOx}$ & $26.7(28)$ & 21.5 & 78.5 & & 10.7 & 39.3 & 17.9 & 32.1 \\
\hline Silica & $13.3(14)$ & 0 & 100 & & 28.6 & 64.3 & 7.1 & \\
\hline Urates & $7.6(8)$ & 37.5 & 62.5 & & 25 & 62.5 & 12.5 & \\
\hline Cystine & $1(1)$ & & 100 & & & 100 & & \\
\hline Mixed & $11.4(12)$ & 41.7 & 58.3 & & 16.7 & 75 & 8.3 & \\
\hline Compounds & $1.9(2)$ & 0 & 100 & & & 50 & & 50 \\
\hline
\end{tabular}

$\mathrm{CaOx}$ calcium oxalate (include monohydrate and dihydrate forms), urates include ammonium urate and sodium urate forms 
Table 2 Frequency of each urolith mineral, based on the size of dog breeds

\begin{tabular}{lll}
\hline Mineral & \multicolumn{2}{l}{ Pure breeds } \\
\cline { 2 - 3 } & Small $(n)$ & Large $(n)$ \\
\hline Struvite & 28 & 1 \\
Calcium oxalate & 18 & 5 \\
Urate & 5 & 3 \\
Silica & 1 & 9 \\
Cystine & & 1 \\
Mixed & 4 & 2 \\
Compounds & 1 & 1 \\
\hline
\end{tabular}

Although in this study we did not have access to the data from urine cultures from the patients, it is reasonable to posit that this pathophysiological mechanism can account for the fact that most cases of struvite urolithiasis included in this study occurred in females, as this gender is more susceptible to urinary tract infection than are males [11].

The second-most common type of urolith was calcium oxalate, which forms in acidic urine oversaturated with calcium and oxalate. Two different mineralogical forms are found in dogs: oxalate dihydrate (weddellite) and monohydrate (whewellite) - although currently this chemical differentiation does not seem to have much clinical significance. In this species, the conditions of hyperoxaluria and hypercalciuria increase the risk of calcium oxalate stones, but hyperadrenocorticism and chronic metabolic acidosis can also be associated with this type of urolith $[12,13]$. Our results are similar to those reported in most epidemiological studies [4-6, 10].

The third most frequent type of urolith was silica, which can represent over $15 \%$ of the total if we add the cases of pure silica uroliths and the two-compound uroliths containing a nidus of silicate. This percentage is significantly higher than that reported in most epidemiological studies, which report values between 0.5 and $0.9 \%$ [4, 7,9] or do not report this mineral $[5,6,8]$. The number even exceeds the proportion of $4 \%$ that we found in a preliminary national study in Mexico [10]. It has been suggested that silica uroliths are due to increased intake of this mineral in the diet. As animal protein contains a low amount of silicate, dietary sources of plant origin or a high silica content in local groundwater [1, 14] may be responsible for the formation of this type of urolith. A possible explanation for the high percentage in our study is that water taken from groundwater near volcanoes contains high levels of silica, and this groundwater is the most important source of water in Mexico City [15]. Nonetheless, our results are actually lower than those obtained in a unique study in Kenya, which reported that in a $53 \%$ prevalence of urolithiasis in native crossbreed dogs, $100 \%$ of the uroliths were silica [14].

Urate uroliths were the fourth most prevalent in our study, with values similar to those cited in most studies [4-7, 9, 10]. Almost all cases involved male Dalmatians; the composition of uroliths was ammonium urate.

The most common mineral mixtures in the mixed uroliths were the two major elements, struvite and oxalate. Comparison with other studies presents difficulties because only some of them $[4,9,10]$ reported mixed uroliths and compounds separately.

In our study, small breeds were most commonly affected by urolithiasis. This predisposition may be related to a lower volume of urine and less frequent micturition, thus leading to a higher urinary concentration of minerals [16]. One limitation of this study was a lack of information on the frequency of different breeds within the general and clinic populations in Mexico City. Thus, the relative risk for the formation of different types of uroliths could not be calculated. However, it did appear that schnauzers and poodles were over-represented in the study.

Comparing our results with studies from other countries has enabled us to identify a high frequency of silica uroliths, which we assume is a peculiarity of the

Table 3 Frequency of mineral composition of uroliths from different geographical areas

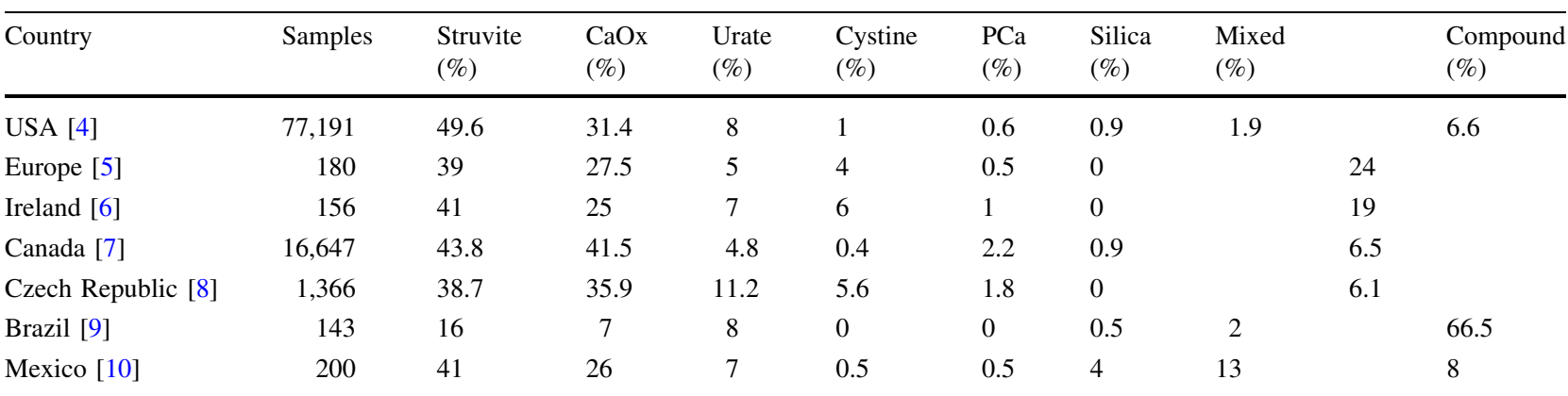

$\mathrm{CaOx}$ calcium oxalate, $\mathrm{PCa}$ calcium phosphate 
geographical location of Mexico City, but more in-depth studies are needed to understand the pathophysiology of this type of urolith formation and to explain, for instance, the reasons that we have detected it only in large breed male dogs.

Acknowledgments This work has been partially supported by a project of Waltham Foundation in Mexico.

\section{References}

1. Lulich JP, Osborne CA, Bartges JW, Lekcharoensuk C (2000) Canine lower urinary tract disorders. In: Ettinger SJ, Feldman EC (eds) Textbook of veterinary internal medicine-diseases of dog and cat, 5th edn. Saunders, Philadelphia, pp 1747-1781

2. Brown NO, Parks JL, Greene RW (1977) Canine urolithiasis: retrospective analysis of 438 cases. J Am Vet Med Assoc $170: 414-418$

3. Wallerström BI, Wagberg TI (1992) Canine urolithiasis in Sweden and Norway: retrospective survey of prevalence and epidemiology. J Small Anim Pract 33:534-539. doi:10.1111/ j.1748-5827.1992.tb01047.x

4. Osborne CA, Lulich JP, Polzin DJ, Sanderson SL, Koehler LA, Ulrich LK, Bird KA, Swanson LA, Pederson BS, Sudo SZ (1999) Analysis of 77, 000 canine uroliths. Perspectives from the Minnesota Urolith Center. Vet Clin North Am Small Anim Pract 29:17-37

5. Stevenson AE, Markwell PJ, Kasidas GP (2000) Quantitative analysis of canine uroliths within Europe in 1999 (abstract). J Vet Int Med 14:383. doi:10.1111/j.1939-1676.2000.tb01174.x

6. Jones BR, Omodo-Eluk AJ, Larkin H, Rogers KD, Sperrin M (2001) Canine uroliths: analysis of uroliths from dogs in Ireland. Irish Vet J 54:629-632

7. Houston DM, Moore AE, Favrin MG, Hoff B (2004) Canine urolithiasis: a look at over 16,000 urolith submissions to the
Canadian veterinary urolith centre from February 1998 to April 2003. Can Vet J 45:225-230

8. Sosnar M, Bulkova T, Ruzicka M (2005) Epidemiology of canine urolithiasis in the Czech Republic from 1997 to 2002. J Small Anim Pract 46:177-184. doi:10.1111/j.1748-5827.2005. tb00308.x

9. Oyafuso MK, Kogika MM, Wirthl VABF, Prosser CS, Coelho BMP, Monteiro PRG (2007) Canine Urolithiasis Study in a veterinary teaching hospital in Sao Paulo, Brazil (abstract). J Vet Int Med 21:646-647. doi:10.1111/j.1939-1676.2007.tb03006.x

10. Del Angel-Caraza J, Chávez Moreno OF, Pérez-García CC (2007) Analysis of canine urolithiasis in Mexico: preliminary results (abstract). J Vet Int Med 21:1432. doi:10.1111/j.19391676.2007.tb01969.x

11. Ling GV, Franti CE, Johnson DL, Ruby AL (1998) Urolithiasis in dogs. III: prevalence of urinary tract infection and interrelations of infection, age, sex, and mineral composition. Am J Vet Res 59(5):643-649

12. Hess RS, Kass PH, Ward CR (1998) Association between hyperadrenocorticism and development of calcium-containing uroliths in dogs with urolithiasis. J Am Vet Med Assoc 15;212: 1889-1891

13. Adams LG, Syme HM (2005) Canine lower urinary tract disease In: Ettinger SJ, Feldman EC (eds) Textbook of veterinary internal medicine-diseases of dog and cat, 6th edn. Saunders, Philadelphia, pp 1850-1874

14. Brodey RS, Thomson R, Sayer P, Eugster B (1977) Silicate renal calculi in Kenyan dogs. J Small Anim Pract 18:523-528. doi: 10.1111/j.1748-5827.1977.tb05924.x

15. Huizar-Alvarez J, Carrillo-Rivera JJ, Angeles-Serrano G, Hergt T, Cardona A (2004) Chemical response to groundwater extraction southeast of Mexico City. Hydrogeol J 12:436-450. doi: 10.1007/s10040-004-0343-3

16. Stevenson AE, Markwell PJ (2001) Comparison of urine composition of healthy Labrador retrievers and miniature Schnauzers. Am J Vet Res 62:1782-1786. doi:10.2460/ajvr.2001.62.1782 